\title{
Diabetic ketoacidosis caused by fulminant type 1 diabetes during adjuvant chemotherapy for colon cancer: A case report
}

\author{
YOSHINORI IWATA, NOBUHISA MATSUHASHI, TAKAO TAKAHASHI, TOMONARI SUETSUGU, \\ MASAHIRO FUKADA, ITARU YASUFUKU, TAKEHARU IMAI, TOSHIYUKI TANAHASHI, SATOSHI MATSUI, \\ HISASHI IMAI, YOSHIHIRO TANAKA, KAZUYA YAMAGUCHI and KAZUHIRO YOSHIDA
}

Department of Surgical Oncology, Gifu University School of Medicine, Gifu, Gifu 501-1194, Japan

Received August 27, 2018; Accepted April 5, 2019

DOI: $10.3892 / \mathrm{mco} .2019 .1862$

\begin{abstract}
Development of diabetic ketoacidosis (DKA) caused by fulminant type 1 diabetes (FT1D) during administration of uracil-tegafur (UFT) with leucovorin (LV) as adjuvant chemotherapy is extremely rare. Here, we report a case of DKA caused by FT1D during administration of UFT with LV as adjuvant chemotherapy for colon cancer. A woman in her 60s was transferred to the emergency medical center of our hospital with complaints of impaired consciousness and vomiting. She had undergone left hemicolectomy and D3 lymph node dissection for transverse colon cancer 8 months earlier. She was provided UFT with LV as adjuvant chemotherapy. Laboratory analysis revealed hyperglycemia, high anion gap metabolic acidosis and urinary ketones. She was diagnosed with DKA and was started on intravenous infusion of fluid and continuous subcutaneous insulin injections. Following admission, she was examined and diagnosed with FT1D. The present case describes an extremely rare case of DKA caused by FT1D during adjuvant chemotherapy with UFT + LV for colon cancer.
\end{abstract}

\section{Introduction}

Most colorectal cancers are adenocarcinomas. The primary treatment method is surgery, which may result in cure depending on the disease stage at diagnosis. We usually perform adjuvant chemotherapy for high risk of recurrence cases. The regimens of adjuvant chemotherapy are various such as 5-fluorouracil (5-FU) + leucovorin (LV), oral uracil-tegafur (UFT) + LV, oral capecitabine, and FOLFOX (oxaliplatin, 5-fluorouracil,

Correspondence to: Dr Nobuhisa Matsuhashi, Department of Surgical Oncology, Gifu University School of Medicine, 1-1 Yanagido, Gifu, Gifu 501-1194, Japan

E-mail: nobuhisa@gifu-u.ac.jp

Abbreviations: DKA, diabetic ketoacidosis; FT1D, fulminant type 1 diabetes; UFT, uracil-tegafur; LV, leucovorin; 5-FU, 5-fluorouracil

Key words: fulminant type 1 diabetes, diabetic ketoacidosis, adjuvant chemotherapy, uracil-tegafur, colon cancer and leucovorin). UFT often causes neutropenia, stomatitis, hand-foot syndrome, and alopecia; however, fulminant type 1 diabetes (FT1D) is a rare complication.

Diabetic ketoacidosis (DKA) is a life-threatening complication of type 1 diabetes (T1D), which leads to death if not treated. FT1D is a subtype of T1D characterized by noticeably rapid and almost complete destruction of pancreatic $\mathrm{B}$ cells, with acute onset leading to severe metabolic disorders. Several studies have reported that interferon alpha or immune checkpoint inhibitors induce FT1D; however, its mechanism of development remains unclear. Here, we report a case of DKA caused by FT1D during administration of UFT with LV as adjuvant chemotherapy for colon cancer.

\section{Case report}

A woman in her $60 \mathrm{~s}$ was transferred to the emergency medical center of our hospital with complaints of impaired consciousness and vomiting. Eight months earlier, she underwent left hemicolectomy and D3 lymph node dissection for transverse colon cancer with perforation. The final pathological diagnosis was Stage II colon cancer (TNM classification: T4bNOM0). The patient had been taking adjuvant chemotherapy with UFT $+\mathrm{LV}$; the dose for UFT and LV was 500 and $75 \mathrm{mg} /$ day, respectively. The patient had been medicated for 28 days with a 14-day washout period; she successfully underwent 4 courses of chemotherapy without any major side effects. During the chemotherapy, she didn't have neither upper respiratory tract nor abdominal symptoms. In the fifth course, she developed impaired consciousness and vomiting on the last day of medication.

Her surgical history included appendectomy. Neither she nor her family had a history of diabetes mellitus. She had no history of drinking or smoking and no known allergies. Upon admission, the Glasgow Coma Scale revealed a score of 11 (E3V3M5). Her abdomen was flat and soft. Laboratory data upon admission are presented in Table I. Arterial blood gas analysis revealed high anion gap metabolic acidosis. Urinalysis was positive for glucose and ketone bodies, and biochemical analyses revealed hyperglycemia. Abdominal computed tomography revealed fatty liver and pancreatic swelling. Based on these findings, the patient was diagnosed with DKA and was started with intravenous fluid infusion and continuous subcutaneous insulin injections. Her blood glucose 
Table I. Laboratory findings on admission.

\begin{tabular}{|c|c|c|}
\hline Variable & Value & Normal ranges \\
\hline \multicolumn{3}{|l|}{ Complete blood count } \\
\hline White blood cell, $\mathrm{mm}^{3}$ & 20,920 & $3,300-7,900$ \\
\hline Red blood cell, $\times 10^{4} / \mu 1$ & 276 & $369-507$ \\
\hline Hemoglobin, g/dl & 10.2 & $11.3-15.4$ \\
\hline Hematocrit, $\%$ & 29.4 & $34.0-46.3$ \\
\hline Platelets, $\times 10^{4} / \mu 1$ & 29.1 & $15.5-35.0$ \\
\hline \multicolumn{3}{|l|}{ Artery blood gas analysis } \\
\hline $\mathrm{pH}$ & 7.138 & $7.35-7.45$ \\
\hline $\mathrm{pO}_{2}, \mathrm{mmHg}$ & 149 & 83-108 \\
\hline $\mathrm{pCO}_{2}, \mathrm{mmHg}$ & 15.8 & $32-48$ \\
\hline $\mathrm{HCO}_{3}, \mathrm{mmol} / \mathrm{l}$ & 5.1 & \\
\hline Lactate, $\mathrm{mg} / \mathrm{dl}$ & 57 & $4.5-14.4$ \\
\hline Base excess, mmol/l & -22.7 & $-3.4-{ }^{+} 1.4$ \\
\hline Anion Gap, mmol/1 & 26.3 & \\
\hline \multicolumn{3}{|l|}{ Urinalysis } \\
\hline $\mathrm{pH}$ & 6.0 & $5.5-7.5$ \\
\hline Protein & $1+$ & $(-)$ \\
\hline Glucose & $2+$ & $(-)$ \\
\hline Ketone bodies & $1+$ & $(-)$ \\
\hline \multicolumn{3}{|l|}{ Biochemistry } \\
\hline AST, IU/1 & 121 & $7-35$ \\
\hline ALT, IU/1 & 84 & $7-40$ \\
\hline LDH, IU/1 & 328 & $125-225$ \\
\hline$\gamma-\mathrm{GTP}, \mathrm{IU} / 1$ & 26 & $<70$ \\
\hline ALP, IU/1 & 303 & $130-330$ \\
\hline T-Bil, mg/dl & 0.7 & $0.2-1.2$ \\
\hline CPK, IU/l & 357 & $40-200$ \\
\hline $\mathrm{TP}, \mathrm{g} / \mathrm{dl}$ & 6.7 & $6.5-8.2$ \\
\hline Alb, g/dl & 4.0 & $3.9-4.9$ \\
\hline T-chol, mg/dl & 128 & $130-220$ \\
\hline Triglyceride, mg/dl & 33 & $50-150$ \\
\hline $\mathrm{Na}, \mathrm{mmol} / \mathrm{l}$ & 135 & $135-147$ \\
\hline $\mathrm{K}, \mathrm{mmol} / \mathrm{l}$ & 4.7 & $3.5-4.8$ \\
\hline $\mathrm{Cl}, \mathrm{mmol} / \mathrm{l}$ & 98 & $97-108$ \\
\hline Amylase, IU/l & 69 & $33-120$ \\
\hline BUN, mg/dl & 48.7 & $8.0-20.0$ \\
\hline Creatinine, $\mathrm{mg} / \mathrm{dl}$ & 1.22 & $0.40-0.80$ \\
\hline C-reactive protein, $\mathrm{mg} / \mathrm{dl}$ & 1.14 & $<0.20$ \\
\hline Glucose, mg/dl & 834 & $70-110$ \\
\hline HbA1c, \% & 6.5 & $4.6-6.2$ \\
\hline Ketone bodies, $\mu \mathrm{mol} / 1$ & 1,1973 & $<130$ \\
\hline
\end{tabular}

AST, aspartate transaminase; ALT, alanine transaminase; LDH, lactate dehydrogenase; ALP, alkaline phosphatase; T-Bil, total bilirubin; CPK, creatine phosphokinase; TP, total protein; Alb, albumin; $\mathrm{T}$ Chol, total cholesterol; BUN, blood urea nitrogen.

level gradually improved, and feeding and intensive insulin therapy was initiated on day three after admission. Laboratory findings on day four are presented in Table II. Each exocrine pancreatic enzyme was remarkably elevated. Her urinary
Table II. Laboratory findings on the fourth day after admission.

\begin{tabular}{lcc}
\hline Exocrine pancreatic enzyme & Levels & Normal ranges \\
\hline Amylase, IU/1 & 223 & $33-120$ \\
Lipase, U/l & 414 & $11-53$ \\
Trypsin, ng/ml & 1,760 & $100-550$ \\
Elastase1, ng/ml & 2,930 & $<300$
\end{tabular}

C-peptide level after admission was $0.1 \mu \mathrm{g} / \mathrm{day}$, whereas fasting serum C-peptide level was $0.01 \mathrm{ng} / \mathrm{ml}$. C-peptide level remained stable at $0.01 \mathrm{ng} / \mathrm{ml}$ for six minutes after glucagon loading. Both anti-glutamic acid decarboxylase antibody and anti-insulin antibody were negative. We determined that the DKA was caused by FT1D. The patient was discharged on day 22 after admission, and no recurrence has been observed for five years since the radical surgical procedure.

\section{Discussion}

Our patient was provided adjuvant chemotherapy with UFT (500 mg/day) + LV (75 mg/day). The patient did not have a history of alcohol or drugs and had undergone four courses of chemotherapy without any major side effects. She developed impaired consciousness and vomiting on the last day of medication during the fifth course of chemotherapy.

Because of the marked insulin deficiency and increased levels of the insulin counter-regulatory hormones cortisol and adrenaline, high levels of plasma glucose ( $\geq 300 \mathrm{mg} / \mathrm{dl}$ ), hyperketonemia (increase of $\beta$-hydroxybutyric acid), and acidosis ( $\mathrm{pH},<7.3)$ occur together; this condition is known as DKA (Treatment Guide for Diabetes, 2014-2015). DKA is often considered the initial symptom of T1D, including FT1D. FT1D is a novel subtype of T1D that has been reported in Japan since the end of the 20th century (1). FT1D is characterized by rapid-onset DKA, low $\mathrm{HbA}_{\mathrm{lc}}$ levels, undetectable serum C-peptide concentrations, and negative islet-related autoantibodies (2). Although the pathogenesis of FT1D remains unknown, recent studies indicate its cause as either viral infection or genetic factors, such as HLA-II or CTLA4 CT60 (3-5). In this case, we didn't examine the antibodies against virus and genotyping for HLA-II or CTLA4.

Some studies have reported that interferon alpha induces autoimmune-mediated T1D $(6,7)$. The precise role of interferon alpha in the onset of T1D in humans is unclear; however, interferon alpha is known to promote maturation of dendritic cells and activation of B cells in mice, thereby leading to autoimmune diabetes. Interferon alpha also directly influences pancreatic beta cells by inducing cytokines and enhancing their susceptibility to invasion by diabetogenic T cells (8). In addition, immune checkpoint inhibitors are known to cause endocrine-related adverse events. Although the evidence is limited, some reports have described new-onset T1D after anti-programed cell death-1 therapy (9-13). Their common point is that both interferon alpha and immune checkpoint inhibitors stimulate the immune system.

UFT is an anti-cancer agent (14). Tegafur produces 5-FU by hepatic metabolism. 5-FU acts as an anti-cancer agent by inhibiting RNA synthesis through active metabolites and 
thymidylate synthase activity (15). Co-administration with uracil enhances the inhibition of 5-FU degradation, thereby increasing the concentration of 5-FU (16). UFT is widely used as adjuvant chemotherapy for Stage III colorectal cancer (17); its efficacy has been applied to high-risk Stage II colorectal cancer, such as in cases of perforation $(18,19)$. Although several patients receive UFT, the development of FT1D during chemotherapy is extremely rare. To the best of our knowledge, only one case with FT1D during chemotherapy with UFT has been reported to date. Adachi et al (20) suggested two possible mechanisms for this development. The first is via immune suppression or immunological reaction, and the second is via the effects of thymidine phosphorylase. With regard to the first opinion, UFT have the common feature with interferon alpha and immune checkpoint inhibitors in the point of effect on the immune system, but the reason why other anti-cancer agents induce FT1D is remained. With regard to the second opinion, no reports of FT1D caused by $5-\mathrm{FU}, \mathrm{TS}-1$, or capecitabine exist, although these belong to the same family of fluoropyrimidine anti-cancer agents. The mechanistic differences between UFT and other fluoropyrimidine anti-cancer agents might participate in development of FT1D. More cases and further studies are warranted to investigate the mechanisms of FT1D pathogenesis.

We reported an extremely rare case of DKA caused by FT1D during adjuvant chemotherapy with UFT + LV for colon cancer. The difference in the mechanisms between UFT and other fluoropyrimidine anti-cancer agents might contribute to the development of FT1D. More cases and further studies are warranted to investigate the mechanism of FT1D pathogenesis.

\section{Acknowledgements}

The authors would like to thank Enago (www.enago.jp) for the English language review.

\section{Funding}

The authors have no conflicts of relevant financial interests.

\section{Availability of data and materials}

The datasets used and analyzed during the current study are available from the corresponding author on reasonable request.

\section{Authors' contributions}

YI, NM and KYo participated in the conception and design of the case report, analyzed and interpreted the data and wrote the manuscript. TS, MF, IY, TI, TTan, SM, HI, YT, KYa, NM and TTak evaluated the patient and participated in the therapy. NM, TTak and KYo revised the manuscript for intellectual content. All authors read and approved the final manuscript.

\section{Ethics approval and consent to participate}

Not applicable.

\section{Patient consent for publication}

Written informed consent was obtained by the patient.

\section{Competing interests}

The authors declare that they have no competing interests.

\section{References}

1. Imagawa A, Hanafusa T, Miyagawa J and Matsuzawa Y: A novel subtype of type 1 diabetes mellitus characterized by a rapid onset and an absence of diabetes-related antibodies. Osaka IDDM Study Group. N Engl J Med 342: 301-307, 2000.

2. American Diabetes Association. Diagnosis and classification of diabetes mellitus. Diabetes Care 37 (Suppl 1): S81-S90, 2014

3. Hanafusa T and Imagawa A: Fulminant type 1 diabetes: A novel clinical entity requiring special attention by all medical practitioners. Nat Clin Pract Endocrinol Metab 3: 36-45, 2007.

4. Imagawa A, Hanafusa T, Uchigata Y, Kanatsuka A, Kawasaki E, Kobayashi T, Shimada A, Shimizu I, Maruyama T and Makino H: Different contribution of class II HLA in fulminant and typical autoimmune type 1 diabetes mellitus. Diabetologia 48: 294-300, 2005.

5. Kawasaki E, Imagawa A, Makino H, Uga M, Abiru N, Hanafusa T, Uchigata $\mathrm{Y}$ and Eguchi K: Differences in the contribution of the CTLA4 gene to susceptibility to fulminant and type 1A diabetes in Japanese patients. Diabetes Care 31: 1608-1610, 2008.

6. Fabris P, Betterle C, Floreani A, Greggio NA, de Lazzari F, Naccarato $\mathrm{R}$ and Chiaramonte $\mathrm{M}$ : Development of type 1 diabetes mellitus during interferon alfa therapy for chronic $\mathrm{HCV}$ hepatitis. Lancet 340: 548, 1992.

7. Uto H, Matsuoka H, Murata M, Okamoto T, Miyata Y, Hori T, Ido A, Hirono S, Hayashi K and Tsubouchi H: A case of chronic hepatitis $\mathrm{C}$ developing insulin-dependent diabetes mellitus associated with various autoantibodies during interferon therapy. Diabetes Res Clin Pract 49: 101-106, 2000.

8. Diana J, Simoni Y, Furio L, Beaudoin L, Agerberth B, Barrat F and Lehuen A: Crosstalk between neutrophils, B-1a cells and plasmacytoid dendritic cells initiates autoimmune diabetes. Nat Med 19: 65-73, 2013.

9. Munakata W, Ohashi K, Yamauchi N and Tobinai K: Fulminant type I diabetes mellitus associated with nivolumab in a patient with relapsed classical Hodgkin lymphoma. Int J Hematol 105: 383-386, 2017.

10. Okamoto M, Okamoto M, Gotoh K, Masaki T, Ozeki Y, Ando H, Anai M, Sato A, Yoshida Y, Ueda S, et al: Fulminant type 1 diabetes mellitus with anti-programmed cell death-1 therapy. J Diabetes Investig 7: 915-918, 2016.

11. Hughes J, Vudattu N, Sznol M, Gettinger S, Kluger H, Lupsa B and Herold KC: Precipitation of autoimmune diabetes with anti-PD-1 immunotherapy. Diabetes Care 38: e55-e57, 2015.

12. Hofmann L, Forschner A, Loquai C, Goldinger SM, Zimmer L, Ugurel S, Schmidgen MI, Gutzmer R, Utikal JS, Göppner D, et al: Cutaneous, gastrointestinal, hepatic, endocrine, and renal side-effects of anti-PD-1 therapy. Eur J Cancer 60: 190-209, 2016.

13. Gaudy C, Clévy C, Monestier S, Dubois N, Préau Y, Mallet S, Richard MA, Grob JJ, Valéro R and Béliard S: Anti-PD1 pembrolizumab can induce exceptional fulminant type 1 diabetes. Diabetes Care 38: e182-e183, 2015.

14. Yonekura K, Basaki Y, Chikahisa L, Okabe S, Hashimoto A, Miyadera K, Wierzba K and Yamada Y: UFT and its metabolites inhibit the angiogenesis induced by murine renal cell carcinoma, as determined by a dorsal air sac assay in mice. Clin Cancer Res 5: 2185-2191, 1999.

15. Longley DB, Harkin DP and Johnston PG: 5-fluorouracil: Mechanisms of action and clinical strategies. Nat Rev Cancer 3: 330-338, 2003.

16. Hoff PM and Pazdur R: UFT plus oral leucovorin: A new oral treatment for colorectal cancer. Oncologist 3: 155-164, 1998.

17. NIH consensus conference. Adjuvant therapy for patients with colon and rectal cancer. JAMA 264: 1444-1450, 1990.

18. Benson AB III, Schrag D, Somerfield MR, Cohen AM, Figueredo AT, Flynn PJ, Krzyzanowska MK, Maroun J, McAllister P, Van Cutsem E, et al: American society of clinical oncology recommendations on adjuvant chemotherapy for stage II colon cancer. J Clin Oncol 22: 3408-3419, 2004.

19. Schmoll HJ, Van Cutsem E, Stein A, Valentini V, Glimelius B, Haustermans K, Nordlinger B, van de Velde CJ, Balmana J, Regula J, et al: ESMO consensus guidelines for management of patients with colon and rectal cancer. A personalized approach to clinical decision making. Ann Oncol 23: 2479-2516, 2012.

20. Adachi J, Mimura M, Gotyo N and Watanabe T: The development of fulminant type 1 diabetes during chemotherapy for rectal cancer. Intern Med 54: 819-822, 2015. 